\title{
DIFFICULTIES IN THE ACQUISITION AND USE OF ENGLISH ARTICLES AMONG ADULT PASHTO LEARNERS
}

\author{
Khalil AHMAD*1 \\ Abdul Qadir KHAN ${ }^{2}$ \\ 1,2 University of Azad Jammu and Kashmir Muzaffarabad, Pakistan \\ ${ }^{1}$ khalilahmadphd@gmail.com \\ 2aqkhan8873@yahoo.com
}

Manuscript received 6 August 2019

Manuscript accepted 30 Nov 2019

${ }^{*}$ Corressponding author

https://doi.org/10.33736/ils.1751.2019

\begin{abstract}
The acquisition of the English articles is one of the most difficult areas for the second language learners particularly when there are no articles in the first language of the learners. The purpose of this study is to investigate the difficulties in acquisition and use of the English articles. The study aims at identifying the errors the EFL learners make in using the English articles. Two theoretical approaches regarding noun classification for articles choice were adopted in this study. The data were collected in the form of a gap-fill task from 75 adult Pashto learners of English. The results showed the students used the definite article 'the' and the indefinite article ' $a / a n$ ' more often than the zero article $\varnothing$. In noun types, a few subjects made errors in using articles before count nouns. In the noun phrase environments, the lowest error rate was in referential indefinite while the highest error rate was in generics. The reasons for difficulties in acquiring and using the English articles were found to be mainly the identification of noun types, NPs environments, and language transfer.
\end{abstract}

Keywords: Pashto language, articles, nouns, noun types, noun phrase, noun phrase environments.

\section{Introduction}

It has been generally established that it does not matter whether it is English as a Second Language (ESL) or English as a Foreign Language (EFL) environment, it has been observed that the English articles are very difficult even for the ESL or EFL learners to acquire and use. The acquisition and the use of the English articles 
become even more arduous task especially when there are no articles in the first languages (L1) of the learners (Hasbún, 2009). The English article system is a sort of a touch stone and provides a window into the native speakers' competence. Due to the expertise and automaticity with which the native speakers use articles, they are usually unaware of the difficulties in the English article system. Hewson (2017) has termed the English article system a "psycho-mechanism" (p. 132). According to which the native speakers use articles accurately but actually they are unaware of the use. They do not apply any formal rules for the articles. They automatically use them without being conscious as to how they are being used.

Even though the system of the English articles is difficult to learn but formal teaching of the English articles can positively influence on the acquisition of the English articles (Master, 1997). Therefore, many teachers try their best to provide and teach rules for the use of articles.

\section{The English Articles}

The English article system consists of three articles: (1) the definite article, i.e. 'The', (2) the indefinite article, i.e. 'a/an', and (3) the zero article, i.e. $\Phi$. The definite article 'the' is used to show definite aspect of an NP. According to Bickerton (1981), an entity is definite provided if the hearer knows about it, unique in a given context or in the universe or usually known as a class that exists in the real world. The function of 'the' is to denote or to show that both the speaker and the hearer know and identify the entity referred to.

As stipulated by Master (1997), the indefinite article 'a' makes an entity countable. Hence, it often comes before singular count nouns. In addition, it is used to signal a generic noun, when it represents a class. It also precedes mass nouns in a special context. The indefinite article is realized as a before words beginning with consonantal sounds and as 'an' used before words beginning with vowel sounds.

Zero article means when there is a void or no article in front of a noun phrase. All kinds of nouns take the definite article the with the exception of singular proper noun, but the indefinite articles (a/an) and the zero articles ( $\Phi)$ are bound by nominal features: (1) countability (whether a noun is count or non-count) and (2) number(whether a noun is singular or plural).

It is important to note that the decision of what nouns are countable and what nouns are not countable is by no means universal. For example, in Pashto, if someone advises you several times, you say, "He gave me advices." The confusion occurs due to cross-linguistic variation in countability of nouns. In Pashto, 'advice' (Naseehat) is count noun and it has its plural form (Naseehatuna) which corresponds to 'advices'. But in English, you can't say, "advices", but rather you would say, "He gave me advice."

\section{Theoretical Background}

The study of the acquisition and the use of the English articles by non-native speakers has been conducted from the perspective of noun classification (CelceMurcia \& Larsen-Freeman, 1999; Hawkins, 2001; Master, 1990), and noun phrase 
environments (Bickerton, 1981; Huebner, 1983; Ionin, Ko, \& Wexler, 2004), and L1 transfer (Bataineh, 2005; Crompton, 2011).

Bickerton's (1981) semantic wheel approach for the reference of noun phrase makes the first appearance which is distinguished by the semantic features, $[ \pm$ Specific Referent $( \pm S R)]$ and $[ \pm$ Assumed Known to the Hearer $( \pm \mathrm{HK})]$. His semantic model has been used by the later studies (Huebner, 1983; Master, 1987; Parrish 1987; Tarone \& Parrish, 1988; Thomas, 1989; Young 1996).

\section{Noun phrase (NP) environments approach.}

The research about the acquisition of articles and the identification of the environments for placing the article before an NP go together. In this regard Huebner's (1983) categorization has been a richer source for the discussion of English noun phrase environments. Huebner's model was itself based on Bickerton (1981). Huebner categorized noun phrase (NP) environments into four types which facilitated the decisions as to which article should be used in which environment:

1. Generic or non-referential definite ${ }^{1}[-\mathrm{SR},+\mathrm{HK}]$ : An NP which refers to a class or a category or a noun phrase (NP) that points to a non-specific entity which the hearer knows, e.g. The cat is a feline animal.

2. Referential definite $[+S R,+H K]$ : A noun phrase that points to an entity which is not only specific but also the hearer knows about it, e.g. He is the president of the committee.

3 .Referential indefinite [+SR, $-H K]$ : A noun phrase that points to a specific entity, which the hearer does not know, e.g. My son brought a rabbit.

4. Non-referential indefinite [-SR, -HK]: An NP that refers to a referent which is neither specific nor known to the hearer, e.g. We need to write an essay.

Besides, these four contexts idiomatic expressions were classified by Butler (2002) and Thomas (1989) as context 5.

\section{Noun classification approach.}

Celce-Murcia and Larsen-Freeman (1999) considered the categorization of the nouns as an important factor for choosing the accurate article. The appropriate article decisions before nouns are dependent on classifications of common versus proper, count versus non-count, and singular versus plural. The concept of noun classification and noun phrase environments presents a special difficulty for the learners for whom English is a second language.

\footnotetext{
${ }^{1}$ The abbreviations in the notations are $+\mathrm{SR}=$ Specific Reference, $-\mathrm{SR}=$ Non-specific Reference, $+\mathrm{HK}=$ Known to the Hearer, $-\mathrm{HK}=$ Unknown to the Hearer. They are found in different combinations according to the contexts.
} 


\section{The Study}

There is a large number of research studies conducted on the acquisition of English articles by the learners of English. However, very limited study has been conducted about acquisition and use of the English articles by the Pashto (L1) learners of English (L2). Although the Pashto language does not have an articles system like that of English, yet definiteness and indefiniteness to some extent are conveyed through the linguistic markers such as demonstratives or indefinite numerals. The Pashto language has no article system. The articles are assumed either to be in-built in the noun phrase or is represented by indefinite numeral such as /yow/ (one), or by the demonstrative pronouns" (Raverty, 1860).

In Pashto, the demonstratives such as /da/ (this), hagha (that), /dwi/ (these) and haghwi (those) are used for referring to someone or something about which the speaker and the listener know. Therefore, the demonstratives are used for the features [+referential, +definite]; while the numeral indefinite /yaw/ (one) is used for [+referential, -indefinite], i.e. generic nouns. Demonstratives, in Pashto, may be equated in function to the definite article (the) in English. The study, therefore, investigates acquisition and use of the English articles based on noun types on one hand, and the different noun phrase environments. On the other hand, in order to address the issue and provide greater insight on use of the English articles by adult Pashto (L1) learners.

It is anticipated that this study will provide a more complete account on acquisition and use of English articles in the scenario of the actual difficulties in article choice for the Pashto learners (L1) of English (L2) and other comparable EFL learners. The study looks into the matter and identifies the types and the loci (in noun types or in noun phrase environments) of errors made by the adult Pashto (L1) speakers of English (L2) in using the English articles. The main research question of this study is "What, where and why do the adult Pashto learners of English make errors while using English articles in the contexts of noun types and noun phrase environments?".

For the research question, it is predicted that in noun types, the learners will make few errors in the count nouns, but they are liable to make errors in using the articles before the non-count nouns, abstract nouns and proper nouns because of their L1 transfer effect. The count nouns are marked in Pashto for their definiteness and indefiniteness with demonstratives and indefinite numerals. Therefore, where the demonstratives and indefinite numerals in Pashto match with the English articles, then the decision of using articles is easy for them. In cases of non-count, abstract and proper nouns, the problem lies with the identification of a noun as to whether it is singular or plural or whether it is definite or indefinite. This mismatch between the nature of nouns in English and Pashto is being made a base for the prediction that the adult Pashto learners of English will make errors in the choice of articles before the nouns concerned.

As far as the noun phrases environments are concerned, it is anticipated that the learners will make few errors in using articles in referential definite contexts $[+\mathrm{SR},+\mathrm{HK}]$ because the rules for these contexts are usually taught in schools. In remaining four contexts, i.e. generic contexts $[-\mathrm{SR},+\mathrm{HK}]$, referential indefinites $[+\mathrm{SR}$, 
$-H K]$, non-referential indefinites [-SR, -HK] and Idiomatic expressions, they are liable to make errors by taking one context for another.

\section{Methodology}

The design of the study was a cross-sectional one and it utilized quantitative method to examine the acquisition and use of English articles by the adult Pashto (L1) speakers. The data were collected from a sample of 75 randomly selected adult regular students. The subjects were adult native speakers of Yousafzai dialect of Pashto (L1) from Khyber Pakhtunkhwa province (KPK) of Pakistan. They ranged in age from 13 to 24 and none of them had ever been to English speaking country. They were the students of college (Higher Secondary) and University (Tertiary Education). They had been learning English formally in schools since they were five years old. They did not have the opportunity for learning English outside the classrooms. The rationale behind opting for the adult learners is that the linguistic and semantic differences between Pashto and English make a demand on Pashto learners to make a new association between articles (or other linguistic devices) and (in)definiteness. It is in line with the idea of Ellis (2005) that children learn languages implicitly, whereas adults must consciously use explicit strategies to learn a second language.

Data were collected in the form of a 'Gap-fill task'. It was adopted from Master (1994). Master's test is considered a genuine tool for the study for two reasons. Firstly, the test seems to cover almost the entire range of English articles use. Secondly, it is designed to test the English articles use for the non-native speakers of English. Thus, it is also appropriate for the adult Pashto (L1) learners of English (L2). The test (task) consisted of five sections. Each section represented an environment for the noun phrases (NPs) on one hand and the noun types on other hand. A test of the same format (Elicitation task) was designed by Benjamin White (2009) in which there were three noun types (count, non-count and abstract) and six semantic environments for NPs. Master's Gap-fill-task was preferred in the study because it covered all the noun types including proper nouns and all noun phrase environments. Moreover, it was designed for the adult non-native speakers, so it was most suitable for the current study.

This test (gap-fill task) consisted of four noun types (count, non-count, abstract and proper nouns) and five noun phrase environments (contexts), i.e. 1 . Generic [-SR, +HK], 2. Definite [+SR, +HK], 3.Indefinite [+SR, -HK], 4.Non-referential [$\mathrm{SR},-\mathrm{HK}]$ and 5.Idiomatic expressions. A total of 23 gaps were in the task to be filled with the appropriate choice from among the articles (a, an, the, and $\varnothing)$ before a noun phrase (NP). The task was administered in a single seating and the duration of filling the gaps was 45 minutes.

\section{Data Analysis Procedures}

In the test, a numeral label was given to each optional article in the following way:

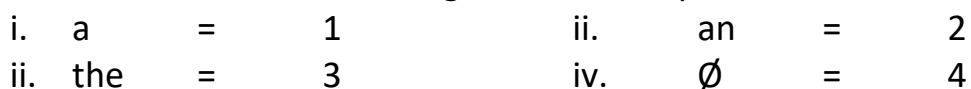


The data from the gap-fill task were written on a separate sheet of paper. 23 blank squares were drawn against each participant. Each blank square represented one gap consecutively. Then the numeral label of each option was put in the relevant square. Thus, 23 squares were for the options. The numeral labels for the 23 article choices of 75 subjects were put into Microsoft Excel 2010. The Excel score was fed into Statistical Analysis Software 9.2 (SAS-9.2) for the calculation of results.

\section{Results and Discussion}

The results are discussed according to the theoretical backgrounds explained earlier. At first, the results are discussed in accordance with the aim of the study, i.e. the identification of errors and their types made by the adult Pashto learners of English both in noun phrase environments and noun types. Secondly, the research question is assessed in the light of the results obtained as to whether it has been answered or not.

\section{Identification of Errors}

The errors made by the students in the test were identified and classified into three kinds: Errors of omission, errors of oversuppliance or commission, and errors of confusion or fluctuation. The names of the categories of errors were adopted from Wang (2010). The scrutiny of the scores of errors in Table 1 is done based on the categories of errors.

Table 1

Classification of errors in use of the English articles

\begin{tabular}{ccc}
\hline Types of errors & Number of errors & Percentage of errors \\
\hline Errors of omission & 293 & 16.99 \\
Errors of oversuppliance & 128 & 7.41 \\
Errors of confusion & 88 & 5.1 \\
\hline Total number of errors & $\mathbf{5 0 9}$ & $\mathbf{2 9 . 5}$ \\
\hline
\end{tabular}

\section{Errors of omission.}

When a gap before an NP is filled with $\varnothing$, where the indefinite article ' $a$ /an' or the definite article 'the' is the actual candidate. This error is called the error of omission. The number of errors of omission is 293 with $16.99 \%$ which is the highest as compared to the other errors. However, one point should be noticed. It is impossible to tell whether the students thought ' $\phi$ ' was the correct answer for a certain blank according to their knowledge or they just haphazardly filled in ' $\varnothing$ ' without knowing why, since in both situations, they filled $\varnothing$ in that blank. 


\section{Errors of oversuppliance or overuse.}

The errors of oversuppliance occur when a gap before an NP is filled with the indefinite article ' $a / a n$ ' or the definite article 'the' whereas, the zero article ' $\varnothing$ ' is the actual candidate. The number of errors of oversuppliance is shown in Table.1 above. The number of errors of oversuppliance is 128 , i.e. $7.41 \%$.

\section{Types of oversuppliance.}

The oversuppliance of articles can be categorized into two categories in order to see which kind of article is incorrectly used more often in the context which actually requires the zero article $\varnothing$ : first, overusing the indefinite article (a/an) to replace zero article $(\varnothing)$; second, overusing the definite article (the) to replace zero article $(\varnothing)$. The numbers for these two types of errors are listed in the following Table 2.

Table 2

The number of errors based on the types of oversuppliance

\begin{tabular}{cccc}
\hline $\begin{array}{c}\text { Types of } \\
\text { oversuppliance }\end{array}$ & $\begin{array}{c}\text { Oversuppliance of } \\
\text { a, an }\end{array}$ & $\begin{array}{c}\text { Oversuppliance of } \\
\text { the }\end{array}$ & $\begin{array}{c}\text { Total no of } \\
\text { oversuppliance }\end{array}$ \\
\hline $\begin{array}{c}\text { Number } \\
\%\end{array}$ & 5 & 123 & 128 \\
\hline
\end{tabular}

Based on the results in Table.2, it can be discovered that most students overuse the definite article (the) rather than the indefinite article (a/an) when the gap actually needs the zero article $(\varnothing)$.

Moreover, the number of errors of overusing 'the' is unbelievably higher than a/an. This forms a striking contrast between the two types of oversuppliance errors. This is possibly because of the effect of transfer of training. As the indefinite article a/an sometimes can be equated to the number "one" in the Pashto language while the definite article has absolutely no equivalent in Pashto, teachers tend to put more emphasis on the definite articles 'the' than the indefinite article when teaching the articles. Therefore, students correspondingly pay more attention to learning the definite article and more often use the definite article 'the.'

The overusing of the definite article 'the' may show two points. First, the students might know some rules about the use of 'the' in different kinds of contexts, but they may still not know all the rules. This goes against the proposal of Yamada and Matsuura (1982) that the learners use articles almost randomly. Second, the Pashto learners of English may choose the definite article when they are not sure which article is the correct one. This may be because of overgeneralization of the use of the definite article and transfer of training. On one hand, they may overgeneralize the use of 'the' in some contexts, which actually need the other two kinds of articles. And this overgeneralization may be the cause of two types of errors. They may overgeneralize the use of 'the' in some contexts, which actually need the other two kinds of articles. 


\section{Errors of confusion or fluctuation.}

Errors of confusion or fluctuation refer to the errors when the interlocutors get confused whether to use the definite article the or the indefinite article $a / a n$ or vice versa in a gap before an NP. Their indecisiveness put them on the wrong choice and as a result they use a wrong article. They are also called commission errors (Huebner 1983). The errors of confusion are listed in the following Table 3.

Table 3

The number of confusion errors

\begin{tabular}{cccc}
\hline $\begin{array}{c}\text { Types of errors of } \\
\text { confusion }\end{array}$ & $\begin{array}{c}\text { Use of } \boldsymbol{a} / \boldsymbol{a n} \\
\text { instead of } \text { the }\end{array}$ & $\begin{array}{c}\text { Use of the instead } \\
\text { of } \boldsymbol{a} / \boldsymbol{a n}\end{array}$ & $\begin{array}{c}\text { Total number of } \\
\text { errors of confusion }\end{array}$ \\
\hline $\begin{array}{c}\text { Number } \\
\%\end{array}$ & 50 & 38 & 88 \\
\hline
\end{tabular}

The results show that the students do not clearly know the line of separation for when 'a/an' or 'the' should be used. It was suggested by Tania lonin et al. (2004) that the native speakers of article-less languages may fluctuate between selecting the English articles based on definiteness and specificity. This was termed the Fluctuation Hypothesis. As a result of fluctuation, they may use the wrong article.

Errors of confusion are categorized into two kinds in order to see which type of confusion happens mostly. The numbers of errors of different types of confusion are listed in Table. 3 above.

From the data, it is evident that the number of misused ' $a / a n$ ' to replace 'the' is greater (50) than that of misused 'the' when the gap actually requires 'a/an' (38). The students make more errors in using' $a / a n$ ' in place of 'the' which may be a sign that students use 'a/an' in contexts, which require 'the'.

\section{Errors in noun phrase (NP) environments.}

The results showed the frequency of errors which the adult native speakers of Pashto made in using the English articles in five different NP environments are given in the following Table 4.

Table 4

The frequency of errors in different noun phrase environments

\begin{tabular}{cccc}
\hline $\begin{array}{c}\text { Serial } \\
\text { number }\end{array}$ & NP Environments & Frequency of errors & $\%$ \\
\hline 1 & (Generic NPs) [-SR, +HK] & 79 & 35.11 \\
2 & (Referential Definite NPs) [+SR, +HK] & 250 & 33.33 \\
3 & (Referential indefinite NPs) [+SR, -HK] & 72 & 24 \\
4 & (Non-referential NPs)[-SR, -HK] & 72 & 32 \\
5 & (Idioms) & 76 & 33.78 \\
\hline
\end{tabular}


Context- 1 is for generic NPs [-SR, $+\mathrm{HK}$ ], context- 2 is for referential definite NPs [+SR, $+\mathrm{HK}]$, context-3 is for referential indefinite NPs [+SR, $-\mathrm{HK}]$, context-4 is for nonreferential NPs [-SR, -HK] and contest- 5 is for idiomatic expressions.

Context-1 comprised three (3) gaps for the English articles, in which around 35 percent of the learners misused the articles; context- 2 had ten (10) obligatory gaps for the articles in which about 33 percent of the subjects misused articles; context-3 had four (4) gaps for articles in which 24 percent of the subjects made errors; context-4 consisted of three (3) gaps for articles in which 32 percent of the participants made errors; whereas context- 5 also consisted of three (3) gaps in which more than 33 percent of the subjects made errors.

Looking at the statistics in the above five contexts, the results went against the predictions made by the researcher for the research question. The subjects made most errors in using articles in generic context [-SR, $+\mathrm{HK}]$, i.e. $35.11 \%$ contrary to the prediction of the researcher. The lowest error rate is in the referential indefinite context [+SR, -HK], i.e. $24 \%$.

The data suggests that context 1 (Generics) and context 5 (Idioms) require a highest level of sophistication in article use, as they both called for a skilful placement of ' $a$ ', 'the' or 'zero article'. The results for both contexts are inconsistent, and the learners' choices appeared to be at random. The findings directly support Thomas (1989) hypothesis on the generic use of articles, and Liu and Gleason's (2002) conclusion about what they termed 'the cultural use' of articles as being the most difficult to acquire. There is justification for the conclusion: generics are generally rare in the input available to the learners, and idioms must be learned as a whole.

\section{Errors in noun types.}

Different types of nouns need different ways for their use. For example, count nouns have plural forms and need determiners, and non-count nouns have no plural forms and usually do not need determiners before them. As the English article is one kind of determiners, choosing which kind of article to use is sometimes greatly affected by the noun attached to that the article. The adult Pashto learners were assessed in putting the English articles in the gaps before four types of nouns, i.e. count, noncount, abstract and proper. The results for the frequency of errors of each type are given in Table 5.

Table 5

Frequency of errors in the use of articles before different types of nouns

\begin{tabular}{cccc}
\hline Serial number & Noun Type & Frequency of errors & $\%$ \\
\hline 1 & Count nouns & 102 & 22.67 \\
2 & Non-count nouns & 140 & 31.11 \\
3 & Abstract nouns & 158 & 35.11 \\
4 & Proper nouns & 73 & 48.67 \\
\hline
\end{tabular}

In Table 5 above, there are four noun types, i.e. count nouns, non-count 
nouns, abstract nouns and proper nouns. In the six (6) gaps for the articles before the count nouns, 22.67 percent out of 75 participants made errors in using the English articles. In the six (6) gaps before non-count nouns, 31.11 percent learners made errors. In six (6) gaps before the abstract nouns, 35.11 percent students made errors. Whereas in the two (2) gaps before proper nouns, 48.67 percent students misused the articles. It was confirmed by the evidence in the study that learners do not use articles "randomly", as was contrarily suggested by Yamada and Matsuura (1982).

For the part of research question regarding the nature and reasons of errors in the context of noun types, it was hypothesized that in noun types, the learners would make few errors as far as the count nouns are concerned, but they were likely to make errors in using the articles before the non-count nouns, abstract nouns and proper nouns. The results came out to be in line with the hypothesis which is evident from Table.5. Only $22.67 \%$ of 75 learners made errors in count nouns which is the least among other noun types. The reason for this could be ascribed to $L 1$ transfer effect. The count nouns are marked in Pashto for their definiteness and indefiniteness with demonstratives and indefinite numerals. Where the demonstratives and indefinite numerals in Pashto matched with the English articles, then it was easy for them which article to use. In case of non-count, abstract and proper nouns, the problem lies with the identification of a noun as to whether it is singular or plural or whether it is definite or indefinite. This mismatch between the nature of nouns in English and Pashto was made a base for the prediction that the learners would make errors in the choice of articles before the nouns concerned. A similar study was conducted by Snape (2005) in which the Japanese learners of English made the maximum number of errors in using the English articles before non-count nouns. Snape ascribed these errors to L1 interference because the Japanese language does not distinguish between count and non-count nouns.

The highest error rate in using articles before noun type's perspective was that of proper nouns, i.e. $48.67 \%$. There could be several reasons for this. This could be ascribed to the format of the gap-fill task because there were only two candidate gaps in front of the proper nouns, i.e. gap no 13 and gap no 17 which made the error rate comparatively higher. Other reasons could be the transfer of training, L1 transfer effect and overgeneralization. Transfer of training has an impact on use of English articles. "The transfer of training is 'the influences that arise from the way a student is taught (Odlin 1989:18)". In English classes, the students are usually taught that proper noun is written with capital letter and does not take an article. Most of the students made error in the gap 13 which says: Hardys are having a party. The students made omission error and did not fill the gap with the definite article 'the', because they have been taught not to put article before the proper noun or they have overgeneralized the singular proper noun for the plural proper noun. The error order from high to low in the noun types was found to be proper $(48.67 \%)$ > abstract (35.11\%) > non-count (31.11\%) > count (22.67\%).

\section{Conclusion}

The study focused on the difficulties in acquisition and use of English articles by the 
adult Pashto learners and explored the types, nature, and the loci of errors which influenced their choices of using articles. The subjects were given a Gap-fill task prepared from the perspectives of noun types on one hand and noun phrase environment on another hand. The errors made by the subjects were categorized into three types: omission of articles, oversuppliance of articles and confusion of articles.

Then the errors were analyzed from two perspectives, i.e. noun types and the noun phrase environments to identify where they had difficulties.

In noun types, a few subjects made errors in using articles before count nouns (22.67\%), but most of them made errors in case of proper nouns $(48.67 \%)$. In noun phrase environments, the subjects made less errors in referential indefinite NPs (24\%) and more errors in generic NPs (35.11\%). An interesting finding was the patterning of noun types. That is, both abstract nouns and non-count nouns disfavored ' $a$ ' and favored ' $\varnothing$ '. The participants had it right for the non-count nouns, but they had it wrong for the abstract nouns. Instead of choosing ' $a$ ' for singular abstract nouns in indefinite contexts, participants were inclined to choose zero article. Once a noun has been known as to whether it is count noun or non-count, or whether it referential, generic or non-referential, then the learner decides whether an article is essential or not.

In the light of the current study, the researcher suggests a change in learning and teaching styles regarding the use of the English articles in EFL contexts. For the EFL learners, it is necessary to learn and practice both aspects of English nouns, i.e. countability (singular/plural, count/non-count) and definiteness (definite/indefinite). Once the learners learn these both aspects of noun phrases (NPs), the teachers are suggested to teach them different noun phrase environments; to introduce activities that could guide the learners to identify the use of suitable article before the same noun in different environment, e.g. It is a wonderful life VS. Life is beautiful (White 2009).

\section{References}

Bataineh, R. F. (2005). Jordanian undergraduate EFL students' errors in the use of the indefinite. The Asian EFL Journal Quarterly, 7(1), 56-76.

Bickerton, D. (1981). Roots of language. Ann Arbor, 10, 268-284.

Butler, Y. G. (2002). An analysis of the metalinguistic knowledge used by Japanese students in acquiring the English article system. Studies in Second Language Acquisition, 24(3), 451-480.

Celce-Murcia, M., \& Larsen-Freeman, D. (1999). The grammar book: An ESL teacher's course. Boston: Heinle \& Heinle.

Crompton, P. (2011). Article errors in the English writing of advanced L1 Arabic learners: The role of transfer. Asian EFL Journal, 50(1), 4-35.

Ellis, N. (2005). At the interface: Dynamic interaction of explicit and implicit language knowledge. Studies in Second Language Acquisition, 27, 305-352.

Hasbún, L. H. (2009). The use of English articles by a group of EFL learners. Revista de Filología y Lingüística de la Universidad de Costa Rica, 177-189. 
Hawkins, R. (2001). Second language syntax: A generative Introduction. New York, NY: Blackwell.

Hewson, J. (2017). Article and noun in English (Vol. 104). Berlin, Germany: Walter de Gruyter GmbH \& Co KG.

Huebner, T. (1983). A longitudinal analysis of the acquisition of English. Michigan: Karoma Press.

Ionin, T., Ko, H., \& Wexler, K. (2004). Article semantics in L2 acquisition: The role of specificity. Language Acquisition, 12(1), 3-69.

Liu, D., \& Gleason, J. L. (2002). Acquisition of the article the by nonnative speakers of English: An analysis of four non-generic uses. Studies in Second Language Acquisition, 24, 1-26.

Master, P. (1987). A cross-linguistic interlanguage analysis of the acquisition of the English article system. Unpublished Doctorial dissertation, UCLA.

Master, P. (1990). Teaching the English articles as a binary system. TESOL Quarterly, 24, 461-478.

Master, P. (1994). The effect of systematic instruction on learning the English article system. Perspectives on Pedagogical Grammar, 229-252.

Master, P. (1997). The English article system: Acquisition, function, and pedagogy. System, 25, 215-232.

Miller, J. (2005). Most of ESL students have trouble with the articles. International Education Journal, 5(5), 80-88.

Odlin, T. (1989). Language transfer: Cross-linguistic influence in language learning. Cambridge, U.K: Cambridge University Press.

Parrish, B. (1987). A new look at methodologies in the study of article acquisition for learners of ESL. Language Learning, 37, 361-383.

Raverty, H. G. (1860) A Grammar of the Pukhto, Pushtu or the Language of the Afghans. Calcutta, India: Baptist Mission Press.

Snape, N. (2005). The uses of articles in L2 English by Japanese and Spanish learners. Essex Graduate Student Papers in Languages and Linguistics, 7, 1-23.

Tarone, E., \& Parrish, B. (1988). Task-related variation in interlanguage: The case of articles. Language Learning, 38, 21-43.

Thomas, M. (1989). The acquisition of English articles by first- and second-language learners. Applied Psycholinguistics, 10, 335-355.

Wang, F. (2010). English article acquisition: An investigation among Chinese Students. Retrieved from http://www.diva-portal.org/smash/get/diva2:3436 62/FULLTEXT01.pdf

White, B. (2009). Accounting for L2-English learners' article choices. MSU Working Papers in SLS, 1(1).

Yamada, J., \& Matsuura, N. (1982). The use of the English article among Japanese students. RELC Journal, 13, 50-63.

Young, R. (1996). Form-function relations in articles in English interlanguage. In R. Bayley \& D. R. Preston (Eds.), Second language acquisition and linguistic variation (pp. 135-175). Amsterdam, Netherlands: John Benjamin's. 